\title{
Inferences on the effects of selection for feed conversion over meat
} \section{quality traits in broiler}

\author{
José Teodoro de Paiva ${ }^{*}$, Gerson Barreto Mourão², José Bento Sterman Ferraz ${ }^{3}$, Elisângela Chicaroni Mattos ${ }^{3}$, Tércio Michelan Filho ${ }^{4}$ \\ Bárbara Machado Campos ${ }^{5}$, Joanir Pereira Eler ${ }^{3}$, Leila de Genova Gaya ${ }^{6}$
}

\author{
${ }^{1}$ Federal University of Viçosa - Dept. of Animal Science, Av. \\ Peter Henry Rolfs, s/n - 36570-900 - Viçosa, MG - Brazil. \\ 2University of São Paulo/ESALQ - Dept. of Animal Science, \\ Av. Pádua Dias, 11 - 13418-900 - Piracicaba, SP - Brazil. \\ 3University of São Paulo/FZEA - Dept. of Basic Sciences, Av. \\ Duque de Caxias Norte, 225 - 13635-900 - Pirassununga, \\ $\mathrm{SP}$ - Brazil. \\ ${ }^{4}$ Aviagen of Brasil Ltda., Rod. SP 127, km 2,2 - 13500-970 \\ - Rio Claro, SP - Brazil. \\ ${ }^{5}$ State University of Southwestern of Bahia - Dept. of Animal \\ Science and Agriculture, Pça. Primavera, 40 - 45700-000 - \\ Itapetinga, BA - Brazil. \\ ${ }^{6}$ Federal University of São João del-Rei - Dept. of Animal \\ Science, Av. Visconde do Rio Preto, s/n - 36301-160 - São \\ João del-Rei, MG - Brazil. \\ *Corresponding author <teo.paiva@hotmail.com>
}

Edited by: Paulo Cesar Sentelhas

Received November 24, 2016

Accepted January 31, 2017

\section{Introduction}

Brazil ranks second among the major broiler meatproducing countries with approximately 13.14 million tons in 2015, and ranks first as broiler meat exporter worldwide with 4.3 million tons (ABPA, 2016). Several changes in meat quality have been recently reported because of the intense selection process for performance traits in broiler breeding programs (Gaya et al., 2011). At the same time, meat quality traits are increasing their relevance on the market and affect the quality of processed products and consumers' choice, becoming one of the most important aspects to be considered by the poultry industry (Le Bihan-Duval et al., 2008). The measurements of $\mathrm{pH}$, color, water retention ability and tenderness are important indicators of meat quality.

According to Aggrey et al. (2010), feed conversion ratio is a trait highlighted in a selection program, once feed expenses account for a great part of the costs in the broiler industry, and it is economically important the dissemination of genetic profiles to allow feed conversion more efficiently. In this context, the understanding of selection effects for feed conversion ratio on meat quality traits in genotypes commercially used has a great importance in broiler breeding program, since the existence of indirect selection for these variables may represent many losses for the industry.
Genetic variability in feed conversion ratio and meat quality traits has been investigated and heritability for these traits in broilers can be found in the literature, ranging from 0.13 to 0.45 , and 0.04 to 0.48 , respectively (Gaya et al., 2006; Aggrey et al., 2010; Verdal et al., 2011; Howie et al., 2011; Chabault et al., 2012; Felício et al., 2013). However, reports on the co-variation between feed conversion ratio and meat quality traits in commercial poultry are unavailable; therefore, the association between them is so far unknown and should be investigated.

This study aimed to estimate, in a broiler male line, the (co)variance components through Bayesian inference and genetic parameters (heritability and genetic correlations) for feed conversion ratio and meat quality traits to identify the existence of indirect selection for these traits, to define of selection strategies for these variables.

\section{Materials and Methods}

\section{Population and phenotypes}

The selection process in an elite flock of a broiler male line was performed with specific emphasis on performance traits (e.g. body weight and FCR), but mainly on the size of the breast muscle. This population went through a pre selection process at 35 days of age and 
taken to the test of feed conversion ratio (FCR), corresponding variable to amount of food consumed (in $\mathrm{kg}$ ) in relation to weight gain (in $\mathrm{kg}$ ) between the $5^{\text {th }}$ and $7^{\text {th }}$ week of age during 14 days. For this test, the broilers were kept in individual boxes at the same farm. These data were registered between Nov 2002 and Mar 2006, from 33 hatches.

Additionally, information on siblings of these chickens were used, which had their carcass and meat quality traits evaluated, helping in the selection process of the siblings, a program that is called sib test. The meat quality data were collected from 13 elite flocks between Apr 2005 and Mar 2006. The broilers were slaughtered at 44 days of age and corresponded to 13 hatches from the same farm in different periods. The final data set consisted of 504 sires and 3,974 dams. The numerator relationship matrix had 107,154 animals distributed in 6 generations.

Broilers were reared with a vaccine program and nutritional management similar to those recommended for broiler, in a strictly controlled environment, to ensure poultry health and performance. The sib test broilers were submitted to the same rearing conditions of the elite flock and were transported and slaughtered at 44 days of age.

The measurement of initial meat $\mathrm{pH}(\mathrm{pHi})$ was performed in the muscle Pectoralis major in the portion cranio-ventral and upper half, using a digital pHmeter 15 min after slaughtering. Afterward, carcasses were submitted to cooling by immersion with water and ice, under standard temperature at $10{ }^{\circ} \mathrm{C}$ and stored at $0{ }^{\circ} \mathrm{C}$. After $24 \mathrm{~h}$, the final $\mathrm{pH}$ (pHf) was registered (Fernandez et al., 2002). There was a concern about the standardization of pHi registration in this study, since many carcasses were subjected to a waiting period for the $\mathrm{pHi}$ gauging because of the fast flow in the slaughtering line. Once it could compromise the trustworthiness of the pHi registration, not all available carcasses were evaluated for $\mathrm{pHi}$.

Lightness $\left(\mathrm{L}^{*}\right)$, a parameter for meat color, was measured at $24 \mathrm{~h}$ after slaughtering using a portable colorimeter and CIELab scale from the CIELab system (International Comission of I'Eclairage, 1976). The test was performed at the Pectoralis major muscle in a ventral surface, obtained three reading points per sample and registering the average as the determined value.

In addition, a sample of the Pectoralis major muscle was collected and weighed, and placed in an air-filled plastic bag. The sample was submitted to cooling $\left(0^{\circ} \mathrm{C}\right)$ and weighed again after $24 \mathrm{~h}$. The difference in percentage between initial and final weight of this sample corresponded to meat drip loss (DL) (Honikel, 1998). Another sample of the same muscle was weighted, conditioned in a plastic bag and stored in freezer at $-18{ }^{\circ} \mathrm{C}$. The sample was then cooled at $4{ }^{\circ} \mathrm{C}$ and weighed again. The difference in percentage between initial and final weight of this sample corresponded to meat thawing loss (TL) (Galobart and Moran, 2004). This sample was then cooked in an electric oven and cooled at room temperature of which four $2 \times 2 \times 1 \mathrm{~cm}$ parallelepipeds were taken, which were sheared individually with a Warner Bratzler blade and considered the average of the four values as the shear force $(\mathrm{SF})$, given in kgf.

\section{Statistical analysis and estimation of genetic parameters}

The outliers were identified for each trait using the box-plot graph from SAS software (Statistical Analysis System, version 9.2) and were removed from the database. Through the same software, the descriptive statistics of the analyzed traits were also obtained with SAS using the MEANS procedure. The (co)variance components were estimated by the Bayesian approach using the GIBBS3F90 software.

The general model used was: $Y=X b+Z a+e$ in which $Y$ is the vector of dependent variables; $b$ is the vector of systematic effects of contemporary group; a is the vector of random additive genetic effects; $X$ and $Z$ are the incidence matrices associating $b$ and $a$ to $Y$; $e$ is the vector of residual random effect. The statistic adopted model had the following distributions: $Y \mid b, a, e$ $\sim N\left(X b+Z a, I \sigma_{e}^{2}\right) ; b \sim N\left(0, \sum_{\mathrm{b}}\right) ; a \mid \sigma_{a}^{2} \sim N\left(0, A \sigma_{a}^{2} ; e\right)$ $\sigma_{e}^{2} \sim N\left(0, I \sigma_{e}^{2}\right)$ in which $\sum_{\mathrm{b}}$ is a diagonal matrix with high variances to represent non-informative a priori; $\sigma_{a}^{2}$ and $\sigma_{e}^{2}$ are the components of the direct additive genetic variance and residual variance; $A$ is the numerator matrix of coefficient of relationship and $I$ is the identity matrix of equal order to the number of animals with observations.

The evaluation of systematic effects and covariance associated with the traits studied was performed using the GLM (General Linear Models) procedure from SAS software (Statistical Analysis System, version 9.2) and had a level of statistical significance of $5 \%$. For the traits FCR and $\mathrm{DL}$, the contemporary groups were formed by the effects of hatch, sex and age of the dam at birth. For L*, $\mathrm{TL}$ and $\mathrm{SF}$, the contemporary groups gathered the effects of hatch and sex, whilst in the case of pHi and pHf, the contemporary groups were formed only by the hatch effect. Data in which contemporary group had less than five broilers were removed from the analysis. Covariables that were significant for the traits were included in the models: initial meat temperature for $\mathrm{pHi}$; $\mathrm{pHf}$ for $\mathrm{L}^{*}$ and $\mathrm{SF}$; final meat temperature for $\mathrm{DL}$, and initial sample weight for TL. Differences among contemporary groups and covariates were expected for the traits studied, since they were registered at different experimental stages, which should affect their variability.

A total of $1,000,000$ cycles after discarding the 100,000 initial samples used for burn-in were considered for genetic analyses in order to minimize the effects of initial samples. A total of 100 cycles sampling interval was kept to ensure the independence of samples and avoid alto-correlation. Further, 9,000 samples were kept during analysis with POSTGIBBSF90 software. Estimates of genetic parameters (heritability and genetic 
correlations) were determined by samples of the (co) variance components, followed by estimates of means, standard deviation and highest posterior density intervals at $95 \%$ (HPD $95 \%$ ) of their marginal distribution a posteriori.

The diagnosis of network convergence provided by Gibbs Sampler was monitored visually (density, trait and mean graphs) and tested by the Geweke and Raftery \& Lewis convergence criterion, using the Bayesian Output Analysis (BOA) package from the $\mathrm{R}$ software ( $\mathrm{R}$ Development Core Team, 2015).

\section{Results and Discussion}

Descriptive statistics of the traits are presented in Table 1 . The mean of FCR $(1.89(0.24))$ was similar to that given by Aggrey et al. (2010) of 1.84 (0.33) at days 28-35 and $2.00(0.42)$ at days $35-42$ and that by Verdal et al. (2011) of $1.72(0.32)$ at days 17-23, in different experimental meat-type chicken lines. This shows that when broilers with a fast growth genotype are involved, lower FCR rates are expected. The coefficient of variation found for FCR (12\%) was similar to that reported by N'Dri et al. (2006), which was $13 \%$ for a slow-growing line of label-type chickens and lower than those reported by Aggrey et al. (2010), Verdal et al. (2011) and Yuan et al. (2015), from 17.93 to $21 \%, 23 \%$ and $28 \%$, respectively. However, Howie et al. (2011) reported a CV (coefficient of variation) of $7 \%$, when evaluating commercial broiler lines at 35 days selected for high growth rate.

Table 1 - Number of observations (N), means (M), standard deviation (SD), coefficient of variation (CV), and minimum (MIN) and maximum (MAX) values of the traits analyzed.

\begin{tabular}{lcrccrr}
\hline Traits $^{1}$ & N & M & SD & CV (\%) & MIN & MAX \\
\hline FCR & 10.745 & 1.89 & 0.24 & 12 & 1.24 & 2.50 \\
pHi & 937 & 6.12 & 0.18 & 3 & 5.64 & 6.62 \\
pHf & 2.104 & 5.80 & 0.13 & 2 & 5.44 & 6.19 \\
L $^{*}$ & 2.130 & 56.07 & 2.97 & 5 & 47.62 & 63.98 \\
DL (\%) & 2.029 & 2.06 & 0.58 & 28 & 0.30 & 3.70 \\
TL (\%) & 2.124 & 6.45 & 3.21 & 50 & 0.40 & 18.30 \\
SF (kgf) & 2.105 & 1.20 & 0.40 & 34 & 0.30 & 2.40 \\
\hline
\end{tabular}

${ }^{1} \mathrm{FCR}=$ feed conversion ratio; $\mathrm{pHi}=$ initial $\mathrm{pH} ; \mathrm{pHf}=$ final $\mathrm{pH} ; \mathrm{L}^{*}=$ lightness; $\mathrm{DL}=$ drip loss; $\mathrm{TL}=$ thawing loss; $\mathrm{SF}=$ shear force.
The CV for $\mathrm{pHi}$, pHf and $\mathrm{L}^{*}$ were low, with values of $3 \%, 2 \%$ and $5 \%$, respectively, which were similar to those reported by Le Bihan-Duval et al. (2008), Chabault et al. (2012) and Felício et al. (2013), in commercial lines of broilers. The coefficients of variation for the other meat quality traits studied varied from 28 to $50 \%$. The CV for DL was $28 \%$, similar to that reported by Felício et al. (2013) (27.97) and lower than the values reported by Le Bihan-Duval et al. (2008) and Chabault et al. (2012), $63 \%$ and $35 \%$, respectively. The CV for $\mathrm{TL}$ and $\mathrm{SF}, 50 \%$ and $34 \%$, respectively, were higher than the CV from the other meat quality traits. Felício et al. (2013) found higher CV values for these traits (58\% and $36 \%$, respectively), Le Bihan-Duval et al. (2008) and Chabault et al. (2012) reported lower values, $33 \%$ for TL and for SF ranging from $21 \%$ to $27 \%$. The coefficients of variation obtained indicate the existence of different levels of phenotypic variability for the traits analyzed and, consequently, the possibility of genetic gains for all the variables tested, in different intensities.

The magnitudes of the genetic and environmental (co)variance components (Tables 2 and 3) defined the heritability (Table 4) and genetic correlation (Table 5) estimates for FCR and the meat quality traits evaluated in the broiler male line under study.

\section{Heritability estimates}

The heritability estimate found for FCR was high (0.52), suggesting important direct additive genetic effect controlling the expression of this trait. Based on the estimated heritability value, FCR remains an important criterion in selection programs because feed costs represent the greatest expense for broiler production. This estimate found for FCR was higher than estimates reported by Aggrey et al. (2010) and N'Dri et al. (2006), which were $0.41,0.49$ and 0.33 , from a growing broiler control population at days 28-35 and 35-42, and from a commercial slow-growing meat-type line for the $8^{\text {th }}$ to $10^{\text {th }}$ week period, respectively. Howie et al. (2011) also found heritability estimates ranging from moderate to high magnitude for feed conversion ratio in four different commercial broiler lines, from 14 to 35 days, with values from 0.30 to 0.45 , similar to those obtained by Mignon-Grasteau et al. (2004) in commercial chickens between days 13-20 and 20-23, which were 0.27 and

Table 2 - Estimates of variance components for feed conversion ratio and meat quality traits.

\begin{tabular}{lcccc}
\hline Traits $^{1}$ & $\sigma_{a}^{2}(\mathrm{SD})$ & HPD $(95 \%)$ & $\sigma_{e}^{2}(\mathrm{SD})$ & HPD (95 \%) \\
\hline FCR & $183.78(11.95)$ & {$[160.10 ; 206.60]$} & $164.80(7.48)$ & {$[150.00 ; 179.50]$} \\
$\mathrm{pHi}$ & $45.93(16.15)$ & {$[20.06 ; 75.23]$} & $198.91(15.73)$ & {$[168.60 ; 229.20]$} \\
$\mathrm{pHf}$ & $51.03(8.92)$ & {$[33.76 ; 67.44]$} & $75.56(6.20)$ & {$[63.11 ; 87.49]$} \\
$\mathrm{L}^{*}$ & $1.83(0.35)$ & {$[1.16 ; 2.55]$} & $4.71(0.28)$ & {$[4.14 ; 5.26]$} \\
$\mathrm{DL}$ & $412.10(131.09)$ & {$[185.80 ; 680.80]$} & $2656.21(129.74)$ & {$[2385.0 ; 2890.0]$} \\
$\mathrm{TL}$ & $23925.0(4757.4)$ & {$[83.02 ; 198.00]$} & $60971.0(3768.6)$ & {$[53420 ; 68270]$} \\
SF & $137.26(29.86)$ & $607.39(28.66)$ & {$[552.5 ; 664.5]$} \\
\hline
\end{tabular}

${ }^{1} \mathrm{FCR}=$ feed conversion ratio; $\mathrm{pHi}=$ initial $\mathrm{pH} ; \mathrm{pHf}=$ final $\mathrm{pH} ; \mathrm{L}^{*}=$ lightness; $\mathrm{DL}=$ drip loss; $\mathrm{TL}=$ thawing loss; $\mathrm{SF}=$ shear force; $\sigma_{a}^{2}=$ genetic variance $(\mathrm{SD}=$ standard deviation); $\sigma_{e}^{2}=$ environmental variance (SD = standard deviation); HPD $(95 \%)=$ highest posterior density interval. 
Table 3 - Estimates of components of genetic covariance for feed conversion ratio and meat quality traits.

\begin{tabular}{lcc}
\hline \multirow{2}{*}{ rraits $^{1}$} & \multicolumn{2}{c}{ FCR } \\
\cline { 2 - 3 } $\mathrm{pHi}$ & $\sigma_{\text {ala2 }}(\mathrm{SD})$ & $\mathrm{HPD}(95 \%)$ \\
$\mathrm{pHf}$ & $-27.34(33.14)$ & {$[-86.22 ; 38.86]$} \\
$\mathrm{L}^{*}$ & $32.77(19.07)$ & {$[-3.12 ; 68.36]$} \\
$\mathrm{DL}$ & $-5.67(3.72)$ & {$[-12.84 ; 2.14]$} \\
$\mathrm{TL}$ & $-163.11(76.24)$ & {$[-316.00 ;-18.23]$} \\
$\mathrm{SF}$ & $-537.43(451.04)$ & {$[-1.425 .00 ; 341.60]$} \\
${ }^{1} \mathrm{FCR}=$ feed conversion ratio; $\mathrm{pHi}=$ initial $\mathrm{pH} ; \mathrm{pHf}=$ final $\mathrm{pH} ; \mathrm{L}^{*}=$ lightness; \\
$\mathrm{DL}=$ drip loss; TL = thawing loss; $\mathrm{SF}=$ shear force; $\sigma_{\text {ala2 }}=$ genetic covariance \\
(SD) = standard deviation); HPD $(95 \%)=$ highest posterior density interval.
\end{tabular}

Table 4 - Estimates of a posteriori means, standard deviation (SD) and highest density intervals at $95 \%$ (HPD) of heritability $\left(h^{2}\right)$ for feed conversion ratio and meat quality traits.

\begin{tabular}{lcc}
\hline Traits $^{1}$ & $\mathrm{~h}^{2}(\mathrm{SD})$ & $\mathrm{HPD}(95 \%)$ \\
\hline $\mathrm{FCR}$ & $0.52(0.02)$ & {$[0.47 ; 0.57]$} \\
$\mathrm{pHi}$ & $0.17(0.07)$ & {$[0.04 ; 0.30]$} \\
$\mathrm{pHf}$ & $0.37(0.05)$ & {$[0.26 ; 0.48]$} \\
$\mathrm{L}^{*}$ & $0.27(0.04)$ & {$[0.19 ; 0.37]$} \\
$\mathrm{DL}$ & $0.13(0.04)$ & {$[0.06 ; 0.21]$} \\
$\mathrm{TL}$ & $0.28(0.05)$ & {$[0.18 ; 0.37]$} \\
$\mathrm{SF}$ & $0.18(0.03)$ & {$[0.11 ; 0.25]$} \\
\hline
\end{tabular}

${ }^{1} \mathrm{FCR}=$ feed conversion ratio; $\mathrm{pHi}=$ initial $\mathrm{pH} ; \mathrm{pHf}=$ final $\mathrm{pH} ; \mathrm{L}^{*}=$ lightness; $\mathrm{DL}=$ drip loss; $\mathrm{TL}=$ thawing loss; $\mathrm{SF}=$ shear force.

Table 5 - Estimates of a posteriori means, standard deviation (SD) and intervals of highest posterior density at $95 \%$ (HPD) of genetic correlations between feed conversion ratio and meat quality traits.

\begin{tabular}{lll}
\hline Traits $^{1}$ & FCR (SD) & HPD (95 \%) \\
\hline $\mathrm{pHi}$ & $-0.30(0.36)$ & {$[-0.94 ; 0.41]$} \\
$\mathrm{pHf}$ & $0.33(0.18)$ & {$[-0.02 ; 0.64]$} \\
$\mathrm{L}^{*}$ & $-0.30(0.17)$ & {$[-0.64 ; 0.03]$} \\
$\mathrm{DL}$ & $-0.49(0.19)$ & {$[-0.85 ;-0.14]$} \\
$\mathrm{TL}$ & $-0.23(0.19)$ & {$[-0.60 ; 0.14]$} \\
$\mathrm{SF}$ & $-0.50(0.17)$ & {$[-0.85 ;-0.18]$} \\
\hline${ }^{1} \mathrm{FCR}=$ feed conversion ratio; $\mathrm{pHi}=$ initial $\mathrm{pH} ; \mathrm{pHf}=$ final $\mathrm{pH} ; \mathrm{L}^{*}=$ lightness; \\
$\mathrm{DL}=$ drip loss; TL = thawing loss; $\mathrm{SF}=$ shear force.
\end{tabular}

0.32, respectively. However, these estimates diverged from those described by Verdal et al. (2011) and Gaya et al. (2006), who reported low magnitude (0.21 and 0.16, respectively, in experimental broilers at days 17-23 and in a commercial broiler male line from 5 to 7 weeks of age). Since FCR presents a non-normal distribution, presumably the Bayesian inference may allow better heritability estimation than other methods that assume normal distribution of the data. Except for the Bayesian approach used by Aggrey et al. (2010), all other genetic parameters reported in the literature for FCR were obtained by restricted maximum likelihood method.

The heritability estimate obtained confirms FCR ability as a selection criterion in this population. There- after, the genetic selection for this trait may be effective for decreasing feed costs of these poultry. Consequently, it is crucial to know the relationship between FCR and other economical interesting variables, such as meat quality traits. This information is important not only to avoid unfavorable indirect selection, but also to favor desirable selection response.

Heritability estimates for $\mathrm{pHi}$ and $\mathrm{pHf}$ were low to moderate (0.17 and 0.37, respectively; Table 4). Different values for heritability estimates for these traits are reported (Le Bihan-Duval et al., 2008; Chabault et al., 2012; Felício et al., 2013), ranging from low to moderate (0.04 to 0.48$)$. The heritability estimate for $L^{*}(0.27)$ was slightly different from that described by Le Bihan-Duval et al. (2008) and Felício et al. (2013), which reported values of 0.35 and 0.33 , respectively, for this trait in heavy commercial broiler lines at 42 and at 44 days of age. The heritability estimate found for DL (0.13) was low and similar to that reported by Felício et al. (2013), of 0.15, and lower than that described by Le Bihan-Duval et al. (2008), of 0.26 . For TL and SF, the heritability estimates found were moderate to low $(0.28$ and 0.18 , respectively) and similar to those described by Felício et al. (2013), which were 0.24 and 0.19 , respectively.

The differences found between our results and those from the literature could be explained by differences in the population studied and due to different models and methods used to obtain the (co)variance component estimates.

The lowest heritability estimates in this study were found for $\mathrm{pHi}$ and SF. Therefore, these variables seem to be mostly influenced by non-additive genetic and environmental effects, suggesting differences in biochemical and physiological mechanisms that affect the expression of these traits. Thus, different genetic associations between meat quality traits and FCR are expected.

\section{Genetic correlation estimates}

Estimates of genetic correlations between FCR and pHi and between FCR and pHf were moderate (-0.30 and 0.33 , respectively) and indicated that selection for improving FCR may affect both traits. Therefore, broilers with low FCR may have a higher $\mathrm{pHi}$ and, at the same time, they may have a lower pHf. The post-mortem metabolism of the muscle tissue greatly influences meat traits and, mainly the rate and amplitude of acidification, strongly affects the organoleptic and technological parameters of meat quality. Interruption of oxygen supply after bleeding modifies muscle metabolism at the beginning of rigor mortis and the muscle depends on the anaerobic glycolytic pathway to use glycogen in ATP production, producing and accumulating lactic acid. Consequently, the decreasing rate of $\mathrm{pH}$ after slaughtering depends on the activity of glycolytic enzymes (glycolysis rate), whilst the final $\mathrm{pH}$ is determined by the initial glycogen reserves of the muscle (Duclos et al., 2007; Barbut et al., 2008). Further, a low genetic relationship was reported between $\mathrm{pH}$ measured immediately after slaugh- 
tering and final $\mathrm{pH}$ in the acidification process of postmortem muscle fibers (Le-Bihan Duval et al., 2008). The two traits are then susceptible to independent mechanisms of expression, suggesting a distinct genetic control of the expression of these parameters, which may have resulted in differences on their correlation with FCR in the current analysis. In other words, the mechanisms involved in the covariation between these two traits are distinct. However, the standard deviation obtained for the genetic correlation between FCR and pHi exceeded the magnitude of its own estimate and limited itself to the conclusion taken on this value. There was a lower number of observations for $\mathrm{pHi}$ than for the other traits evaluated in this study, which may have contributed to the high standard deviation for this estimate.

The mechanism involving changes within proportions and the speed of the deposition of muscle tissue in selected broilers culminates in the variation of amounts of muscle tissues and enhances structural and metabolic changes with direct impact on sensorial and functional aspects of the meat (Dransfield and Sosnicki, 1999; Felício et al., 2013). Several studies showed that selection for higher weight or muscle mass gain caused histological and biochemical changes in the muscle tissue. Increases in the development of breast muscle in broilers are associated to a significant increase in the size of the muscle fiber (Duclos et al., 2007; Felício et al., 2013). Glycogen reserves at slaughter (glycolytic potential) and post-mortem glycolytic activities decrease as fiber size increases. Consequently, breast muscles with large fibers have higher $\mathrm{pHi}$ and $\mathrm{pHf}$ rates in selected lines when compared to non-selected genotypes (Berri et al., 2001; Duclos et al., 2007).

A pHi increase in broilers may be caused by the selection for improving FCR since lower rates of feed conversion determined lower fat rates (Gaya et al., 2006; N'Dri et al., 2006). Therefore, this selection process could determine a greater percentage of muscle tissue in the carcass, which could change the glycolytic rate of the muscle fiber in broilers. Although there is a decrease in glycolytic activity during the $24 \mathrm{~h}$ after slaughter, the muscle will undergo a process of acidification during the period with subsequent decrease in $\mathrm{pH}$ in $24 \mathrm{~h}$, which may also be affected by selection to improve FCR, despite the negative correlation of the glycolytic capacity with the final pH (Le-Bihan Duval et al., 2008; Alnahhas et al., 2014). Other genetic/biochemical factors may also be affecting the correlation between FCR and $\mathrm{pH}$ variables, which should be further investigated and identified in the population.

The meat of broiler lines selected for increased muscle mass growth have shown a low rate of meat-color, which is related to a decrease of the glycogen stock level in muscle fibers (Duclos et al., 2007). Low pH conditions after slaughter when carcass temperature is still high may cause denaturation and loss of solubility in muscle proteins and, consequently, decrease in the meat water retention ability with the release of liquid on the surface. Less light may be transmitted through the muscle fibers due to a lower selective absorbance of light by myoglobins and their derivatives. Dispersed light gives a pale color to the meat (Swatland, 2008; Alnahhas et al., 2014). The genetic correlation estimate between FCR and $\mathrm{L}^{*}$ obtained in this study was moderate (-0.30). Therefore, selection for improving FCR increases $\mathrm{L}^{*}$ and affects the aspects of broiler meat in this specific line because of an increase in $\mathrm{L}^{*}$ indicates paleness (Gaya et al., 2011). It is indeed one of the relevant factors that may make the consumer reject the meat.

Since light dispersion from muscle surface is directly proportional to the amount of protein denaturation (Adzitey and Nurul, 2011), results of the genetic correlation between FCR and $\mathrm{L}^{*}$ may be corroborated by the fact that the selection for increasing FCR may decrease $\mathrm{pH}$ in $24 \mathrm{~h}$ after slaughter. Further, low rates in post-mortem muscular $\mathrm{pH}$ impair the water retention ability of the meat by providing poor processing properties with a reduction in product yields and, consequently, economical losses (Duclos et al., 2007).

The traits DL and TL were genetically and antagonistically associated with FCR and estimates of these genetic correlations varied in magnitude. Selection to increase FCR may increase drip and TL, as shown by their genetic correlations of -0.49 and -0.23 , respectively. Therefore, a lower FCR determines higher water losses by drip and a lower degree in water loss by thawing.

The water retention ability is one of the most important functional traits in meat since it affects its aspect and taste. It also affects directly the quality of the processed products and, in turn, greatly influences meat tenderness (Duclos et al., 2007). The $\mathrm{pH}$ decrease during the post-mortem period changes cell composition and reduces water retention ability in the muscle proteins due to denaturation. This type of meat is not well accepted by the meat industry because of deficient yield, reduced juiciness and low shelf life of the product when processed (Duclos et al., 2007; Petracci et al., 2015). Although costs in production systems with animals with low FCR should be decreased, selection for this specific trait seems to increase DL and TL, which is a negative factor since it may compromise the functional meat properties in the broiler line studied.

Genetic correlation between FCR and SF was high $(-0.50)$ and indicated a strong and antagonistic genetic association between the variables. In fact, selection to increase FCR may increase meat shear force in the broiler line studied or, in other words, tenderness is reduced. The meat tenderness, measured by shear force results from water losses and is closely related to the amount of intramuscular water and, therefore, to the meat water retention ability (Joo et al., 2013). The greater the water content in the muscle, the higher the meat tenderness, corroborating current results.

Predominant fast-twitch fibers in the muscle tissue, mainly in the breast, obtained contraction energy through the glycolytic pathway. The metabolism con- 
tributes to a fast decrease in $\mathrm{pH}$ in stress conditions with high-energy demand. Consequently, lactic acid is produced and cannot be removed in the post-mortem period. In the case of an increase in fiber size, it may negatively affect meat quality (Scheuermann et al., 2004; Adzitey and Nurul, 2011). Therefore, when CR is increased, the occurrence of a greater diameter in muscle fibers may be indirectly induced with changes in meat quality, as reported in the current analysis.

The genetic correlation estimates previously shown among FCR and DL and TL, $\mathrm{L}^{*}$ and SF suggest that selection to improve FCR may cause important losses to the broiler line studied. FCR is a highly interesting trait for broiler production and is frequently used as a selection criterion in breeding programs. Due to changes in consumption and increased demand for processed meat products, the importance of meat sensorial and technological qualities and the processing capacity in the poultry industry have significantly increased (Petracci et al., 2015). Consequently, broiler-breeding programs should pay great attention to these conditions. Further, studies may elucidate the mechanisms and the genes related to those variables in order to reduced effects on industry when there is a selection for improving FCR by adapting selection criteria and final products to consumers' demands.

The analysis of alternative breeding strategies is highly recommended, comprising the simulation of genetic gains for the evaluated traits and incorporation of favorable criteria to meat quality in the selection indexes of the population. The use of genomic information may also make the selection process in this broiler line more efficient since the genetic correlations between FCR and meat quality traits were not high. More accurate estimates of these parameters by the use of genomic information (Meuwissen et al., 2001) could allow identification of broilers with better FCR and meat quality traits.

Additionally, in broiler chickens, it is known that feed efficiency is usually expressed as the amount of feed intake per body weight gain referred to as FCR. However, a large proportion of the variation in feed intake is due to variability in maintenance requirement, a major contributing factor to feed intake. However, this factor is not accounted in FCR. The residual feed intake (RFI) accounts for both maintenance requirements and growth (Aggrey et al., 2010). High heritability estimate for RFI was reported by Verdal et al. (2011) in broilers between 17 and 23 days $(0.46)$, similar to those reported by Aggrey et al. (2010) in meat-type chickens from two age periods: 28 to 35 days (0.45) and 35 to 42 days (0.42). Thus, direct selection to modify this trait may be efficient for use as selection criteria to improve feed efficiency because of its phenotypic independence of maintenance body weight and body weight gain. Studies on genetic parameters for this variable and others can investigate whether genetic properties of RFI, associated with meat quality, could complement the estimates used to improve feed efficiency in the broiler line studied.

\section{Conclusion}

The selection to improve FCR in the studied population may lead to genetic gains for this trait. However, losses for $\mathrm{L}^{*}$, water retention ability and tenderness may occur due to an indirect selection when FCR is used as a selection criterion. Since these traits are associated with sensorial and functional properties of broiler meat, this selection process to increase FCR may compromise meat processing and acceptance of broiler meat in the market.

The use of FCR as a selection criterion in this population must be monitored and breeding strategies that are aimed at not only broilers growth and performance, but also at qualitative aspects of meat are recommended.

\section{Acknowledgements}

The authors are thankful for the Brazilian National Council for Scientific and Technological Development (CNPq) for the scholarship granted to the first author and for the São Paulo Research Foundation (FAPESP) for the scholarship granted to the last author.

\section{References}

Adzitey, F.; Nurul, H. 2011. Pale Soft Exudative (PSE) and Dark Firm Dry (DFD) meats: causes and measures to reduce these incidences. International Food Research Journal 18: 11-20.

Aggrey, S.E.; Arthur, B.K.; Sebastian, B.; Anthony, N.B. 2010. Genetic properties of feed efficiency parameters in meat-type chickens. Genetics Selection Evolution 42: 25.

Alnahhas, N.; Berri, C.; Boulay, M.; Baéza, E.; Jégo, Y.; Baumard, Y.; Chabault, M.; Le Bihan-Duval, E. 2014. Selecting broiler chickens for ultimate $\mathrm{pH}$ of breast muscle: analysis of divergent selection experiment and phenotypic consequences on meat quality, growth, and body composition traits. Journal of Animal Science 92: 3816-3824.

Associação Brasileira de Proteína Animal [ABPA]. 2016. Annual report $=$ Relatório anual. Available at: http://abpa-br.com. br/storage/files/versao_final_para_envio_digital_1925a_final_ abpa_relatorio_anual_2016_portugues_web1.pdf. [Accessed May 30, 2016] (in Portuguese).

Barbut, S.; Sosnicki, A.A.; Lonergan, S.M.; Knapp, T.; Ciobanu, D.C.; Gatcliffe, L.J.; Hulf-Lonergan, E.; Wilson, E.W. 2008. Progress in reducing the pale, soft and exudative (PSE) problem in pork and poultry meat. Meat Science 79: 46-63.

Berri, C.; Wacrenier, N.; Millet, N.; Le Bihan-Duval, E. 2001. Effect of selection for improved body composition on muscle and meat characteristics of broilers from experimental and commercial lines. Poultry Science 80: 833-838.

Chabault, M.; Baéza, E.; Gigaud, V.; Chartrin, P.; Chapuis, H.; Boulay, M.; Arnould, C.; D'Abbadie, F.; Berri, C.; Le BihanDuval, E. 2012. Analysis of slow-growing line reveals wide genetic variability of carcass and meat quality-related traits. BMC Genetics 13: 90.

Comission International De L'Eclairage [CIE]. 1976. Colorimetry. 2ed. CIE, Vienna, Austria. 
Dransfield, E.; Sosnicki, A.A. 1999. Relationship between muscle growth and poultry meat quality. Poultry Science 78: 743-746.

Duclos, M.J.; Berri, C.; Le Bihan-Duval, E. 2007. Muscle growth and meat quality. The Journal of Applied Poultry Research 16: 107-112.

Felício, A.M.; Gaya, L.G.; Ferraz, J.B.S.; Moncau, C.T.; Mattos, E.C.; Santos, N.P.; Michelan Filho, T.; Balieiro, J.C.C.; Eler, J.P. 2013. Heritability and genetic correlation estimates for performance, meat quality and quantitative skeletal muscle fiber traits in broiler. Livestock Science 157: 81-87.

Fernandez, X.; Santé, V.; Baeza, E.; Le Bihan-Duval, E.; Berri, C.; Rémignon, H.; Babilé, R.; Le Pottier, G.; Astruc, T. 2002. Effects of the rate of muscle post mortem $\mathrm{pH}$ fall on the technological quality of turkey meat. British Poultry Science 43: 245-252.

Galobart, J.; Moran, E.T. 2004. Freeze-thaw and cooking effects on broiler breast fillets with extreme initial L* values. Poultry Science 83: 2093-2097.

Gaya, L.G.; Ferraz, J.B.S.; Rezende, F.M.; Mourão, G.B.; Mattos, E.C.; Eler, J.P.; Michelan Filho, T. 2006. Heritability and genetic correlations estimates for performance, carcass and body composition traits in a male broiler line. Poultry Science 85: 837-843.

Gaya, L.G.; Mourão, G.B.; Ferraz, J.B.S.; Mattos, E.C.; Costa, A.M.M.A.; Michelan Filho, T.; Rosa, A.F.; Felício, A.M.; Eler, J.P. 2011. Estimates of heritability and genetic correlations for meat quality traits in broilers. Scientia Agricola 68: 620-625.

Honikel, K.O. 1998. Reference methods for the assessment of physical characteristics of meat. Meat Science 49: 447-457.

Howie, J.A.; Avendano, S.; Tolkamp, B.J.; Kyriazakis, I. 2011. Genetic parameters of feeding behavior traits and their relationship with live performance traits in modern broiler lines. Poultry Science 90: 1197-1205.

Joo, S.T.; Kim, G.D.; Hwang, Y.H.; Ryu, Y.C. 2013. Control of fresh meat quality through manipulation of muscle fiber characteristics. Meat Science 95: 828-836.

Le Bihan-Duval, E.; Debut, M.; Berri, C.M.; Sellier, N.; SantéLhoutellier, V.; Jégo, Y.; Beaumont, C. 2008. Chicken meat quality: genetic variability and relationship with growth and muscle characteristics. BMC Genetics 9: 53.
Meuwissen, T.H.E.; Hayes, B.J.; Goddard, M.E. 2001. Prediction of total genetic value using genome-wide dense marker maps. Genetics 157: 1819-1892.

Mignon-Grasteau, S.; Muley, N.; Bastianelli, D.; Gomez, J.; Péron, A.; Sellier, N.; Millet, N.; Besnard, J.; Hallouis, J.M.; Carré, B. 2004. Heritability of digestibilities and divergent selection for digestion ability in growing chicks fed a wheat diet. Poultry Science 83: 860-867.

N'Dri, A.L.; Mignon-Grasteau, S.; Sellier, N.; Tixier-Boichar, M.; Beaumont, C. 2006. Genetic relationships between feed conversion ratio, growth curve and body composition in slowgrowing chickens. British Poultry Science 47: 273-280.

Petracci, M.; Mudalal, S.; Soglia, F.; Cavani, C. 2015. Meat quality in fast-growing broiler chickens. World's Poultry Science Journal 71: 363-374.

Scheuermann, G.N.; Tuzun, S.; Mulvaney, D.R. 2004. Comparison of chicken genotypes: myofiber number in Pectoralis muscle and myostatin ontogeny. Poultry Science 83: 1404-1412.

Swatland, H.J. 2008. How $\mathrm{pH}$ causes paleness of darkness in chicken breast meat. Meat Science 80: 396-400.

Verdal, H.; Narcy, A.; Bastianelli, D.; Chapui, H.; Même, N.; Urvoix, S.; Le Bihan-Duval, E.; Mignon-Grasteau, S. 2011. Improving the efficiency of feed utilization in poultry by selection. 2. Genetic parameters of excretion traits and correlations with anatomy of the gastro-intestinal tract and digestive efficiency. BMC Genetics 12:71.

Yuan, J.; Dou, T.; Ma, M.; Yi, G.; Chen, S.; Qu, L.; Shen, M.; Qu, L.; Wang, K.; Yang, N. 2015. Genetic parameters of feed efficiency traits in laying period of chickens. Poultry Science 94: $1470-1475$. 